\title{
Late Middle Palaeolithic Subsistence in the Central Plain of China: A Zooarchaeological View from the Laonainaimiao Site, Henan Province
}

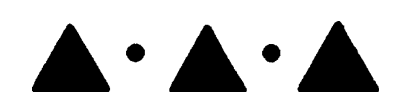

Qu Tongli, Chen Youcheng, Ofer Bar-Yosef, and Wang Youping

\begin{abstract}
This article presents an analysis of faunal remains from Laonainaimiao, a late Middle Palaeolithic site in Henan Province. The site deposit is subdivided into five layers, among which Layer 3 yielded the most abundant archaeological remains including lithics, animal bones, and fireplaces. There are a series of repeated human occupations dating to about 40,000 B.P. Taphonomic observations demonstrate that the animal bones accumulated in Layer 3 are the result of human activities. The assemblage is dominated by horse and aurochs, followed by gazelle, deer, wild boar, and rhinoceros. The equids and bovids show a prime-age dominated profile indicating the capability for hunting large game during the Middle Palaeolithic. According to detailed analysis of skeletal parts, bone fracture patterns, and bone modifications, the carcasses were probably transported to the site whole for butchery. Marrow and grease were fully extracted. The intensive utilization of the carcasses reflects a very high food demand. Such a behavioral pattern may result from lower availability of food due to the palaeoenvironment, seasonality, or group size or from the poor quality of the food, which pushed people to maximize the carcasses. KeYwords: subsistence, hunting, marrow and grease extraction, late Middle Palaeolithic.
\end{abstract}

\section{INTRODUCTION}

The complex nature of the Middle Palaeolithic in East Asia has called for increased attention in recent years. No consensus concerning criteria for identifying the Middle Palaeolithic as recognized in western Eurasia has been reached for East Asia (Gao and Norton 2002; Li 2014; Lin 1996; Yee 2012). The issue is whether there was a clear technological change from the Lower to the Middle Palaeolithic and, if so, whether a so-called Middle Palaeolithic as a stage in human cultural evolution can be recognized in East Asia. Studies focused on lithic technology and human fossils have pointed out that the lithic industry dated to the Middle Palaeolithic (ca. 250,000-50,000 B.P. in western Eurasia) is similar to that of the Lower Palaeolithic without any apparent change in techno-typological features. The lithic industry as

$\mathrm{Qu}$ Tongli is an Associate Professor of Archaeology at Peking University. Chen Youcheng is a Lecturer in Archaeology at Capital Normal University. Ofer Bar-Yosef is Professor Emeritus of Anthropology at Harvard University. Wang Youping is a Professor of Archaeology at Peking University. 
documented in many East Asian assemblages is characterized by a simple core and flake industry with little evidence of the Levallois technique that is the most common feature of the Middle Palaeolithic in central and western Eurasia. One exception, according to reported discoveries, is the presence of this technique at Shuidonggou, Loc. 1 in Ningxia. There, the layer which contains Levalloisian blade technology is dated to ca. 43,000 B.P. (Boëda et al. 2013; Nian et al. 2014; Ningxia 2003). This example indicates that the Levallois technique can be found in the western region of China between the Upper Yellow River and the Altai mountains. Most recently, Levallois technique has been found in Xinjiang and Inner Mongolia (Li et al. 2018; Yu and He 2017). Moreover, some archaeologists have suggested that the presence of the discoidal core technique during the Late Pleistocene of China reflects a technological distinction between the Lower and the Middle Palaeolithic (Chen and Qu 2016; Yee 2012). However, this proposal is not commonly accepted for defining the Chinese Middle Palaeolithic in the Chinese mainland (Li 2014).

The ongoing debate concerning the Chinese Middle Palaeolithic tends to focus on the signatures of lithic technological organization. It has been recognized, however, that other aspects of the archaeological record that provide evidence of subsistence strategies, use of landscape, patterns of mobility, or cognitive and biological evolution need to be evaluated in order to determine whether additional cultural changes illustrate the uniqueness of this general period.

Planning behaviors related to subsistence strategies in the Chinese Palaeolithic have barely been discussed previously, partly due to the lack of archaeozoological records from the Middle Palaeolithic period and partly because of the limited number of detailed studies. However, recent research and excavations of the sites attributed to this time period now provide substantial documentation of subsistence practices. For example, Norton and Gao (2008) used a detailed taphonomic analysis to show that hominins at the Xujiayao site in Shanxi Province regularly acquired equids for food in the early Late Pleistocene. Hunting large game such as individual adult wild horses and aurochs has been recognized at the early Late Pleistocene Lingjing site in Henan Province; such evidence marks a significant shift in human planning (Zhang et al. 2011). More data suggesting humans preyed on large animals has been recorded in the lower layer of Ma'anshan (ca. 53,000 B.P.), where bones of water buffalo, rhino, and stegodon accumulated (Zhang et al. 2009).

The faunal remains from the Laonainaimiao site presented here add an additional dataset that allows us to reconstruct food acquisition, transport, and processing behaviors amongst human occupations dated to the late Middle Palaeolithic in the Central Plains of China. The current study reveals the potential for large game hunting through social cooperation as well as the intensification of marrow and grease extraction on site. By focusing on the Equidae, it also documents a strategy shift in Layer $3 \mathrm{~B}$ when compared to earlier deposits, indicating a change in mobility and settlement patterns.

\section{THE LAONAINAIMIAO SITE}

Laonainaimiao is located in Zhengzhou city, the capital of Henan Province in China, situated along the upper valley of Jialu River, a tributary of Huai River (Fig. 1). The local environment is in a temperate climate zone characterized by four seasons and a monsoon system. The cold and dry winter lasts from November through February, 


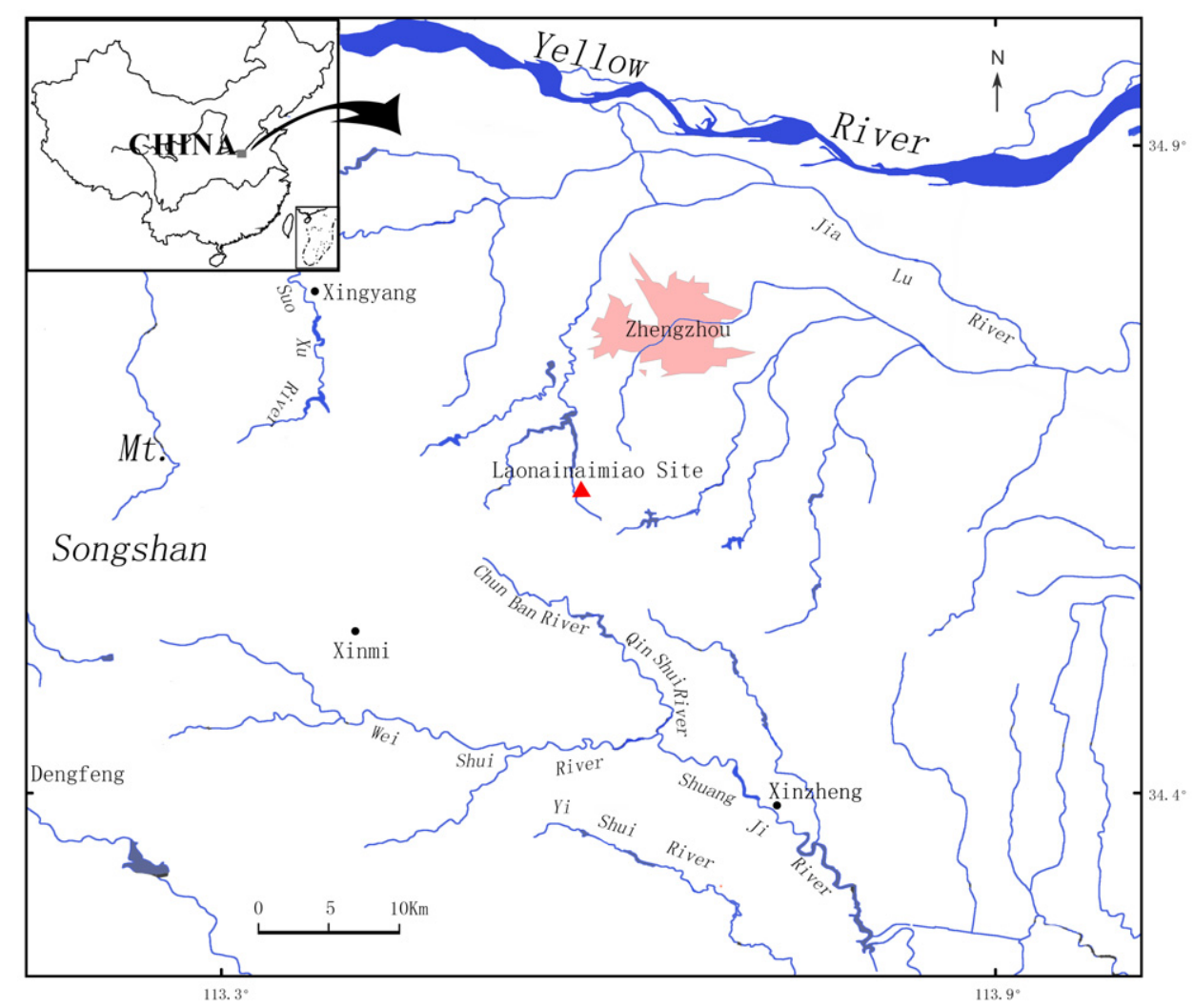

Fig. 1 Geographic location of the Laonainaimiao site.

during which the landmass is controlled by a Siberian high-pressure system with strong winds (Zhao 1994).

Excavations at the site conducted since 2011 exposed a $90 \mathrm{~m}^{2}$ area. The overall stratigraphy is about $6 \mathrm{~m}$ thick, divided into five layers. Layer 1 is surface soil and Layer 2 is mainly composed of disturbed sediment. Layer 3 is divided into five sub-layers labeled 3A-3F. Layer 3 records fine-grained river floodplain deposits interspersed with drier periods; it also documents human occupations ca. 40,000 B.P. (Zhengzhou et al. 2012). Most of the exposed fireplaces are concentrated in Layer 3B and Layer 3F, documenting the two most intensive human occupations at this locality (Chen 2015). Layer 4 is composed of fine-grained river floodplain deposits containing cultural remains, though they are less dense and numerous than those in Layer 3. Layer 5 also records a floodplain deposit, but contains very few cultural remains (Chen 2015).

The site has yielded an abundance of animal bones, burnt bones, ostrich eggshells, archaeobotanical remains, and fireplaces, in addition to a wealth of stone artifacts characterized by a small-flake tool industry and possible fire stones (large sandstone rocks distributed near the fireplaces) (Chen 2015). The site provides important archaeological materials and perspectives on the technology, subsistence, occupation, and mobility patterns of the Middle Palaeolithic population in China. 


\section{BONE ASSEMBLAGES AND TAPHONOMIC HISTORIES}

Here we present faunal data from the Laonainaimiao site with the aim of examining human subsistence in detail. We discuss human behaviors and planning capacities in acquiring, transporting, and processing animals for food. This information extends our understanding of the lifeways of foragers during the late Middle Palaeolithic period in the Central Plains and provides new perspectives on identifying the Chinese Middle Palaeolithic.

This report focuses on the bone assemblages from Layer 3F and Layer 3B. All the data presented here were derived from the 2011-2013 excavations. The area of the site was gridded in $1 \times 1 \mathrm{~m}$ units and each square was further divided into four $50 \times 50 \mathrm{~cm}$ sub-squares. Recovered materials larger than $2 \mathrm{~cm}$ were piece-plotted. Areas with very dense findings underwent dry-sieving through a $3 \mathrm{~mm}$ mesh.

Thus far, 3842 bones (including eggshells) have been coordinated in situ from Layer 3F and Layer 3B. In Layer 3F, 2.5 percent of the specimens are burnt, while 1.1 percent are burnt in Layer 3B. Of the total specimens, 145 pieces of eggshell from Layer 3F and 6 pieces from Layer 3B were identified as ostrich; an additional 1508 bones from Layer 3F and 1425 bones from Layer 3B were identified to taxon and body size group. Excepting unidentifiable pieces, any piece of bone that could not be identified to taxon was classified by body size. For example, due to a high degree of fragmentation, ribs were rarely identified to any degree of taxonomic specificity. Instead, they were classified according to mammal size, including 53 rib fragments from large mammals, 79 fragments from medium-sized mammals, and 20 pieces from small mammals. Overall, large and medium-sized mammals constitute 39.6 percent of the total assemblage, while extra large, small, and extra-small sized mammals are only represented in very small proportions (Table 1). Although the main bone records originate from large and medium-sized mammals, this does not mean that small or very small animals, as well as aquatic resources, made no contribution to the assemblage or were not associated with subsistence. (A full-scale program of work sieving, particularly water sieving, is expected to be conducted along with further excavation in order to collect and study specimens in smaller size classes.)

The common species found in the two assemblages reflect stable palaeoenvironmental conditions characterized by a wide-open landscape of grass steppe with patches of forest. Equidae and Bos primigenius are the most common taxa in Layer 3F, followed by Cervidae, Gazella, and Sus scrofa. Equidae is dominant in Layer 3B, while the frequencies of Bos primigenius decrease remarkably compared with Layer 3F. There is also a sharp reduction in the presence of ostrich eggshells. The proportions of mediumsized mammals and small mammals increase in Layer 3B, however.

We evaluated the taphonomic history of the Laonainaimiao site by examining the degree of bone weathering, fragmentation, density-mediated attrition and surface modifications, and sedimentation. Bone cortical preservation is comparatively good in the Layer 3F and Layer 3B assemblages. The high proportions of lightly weathered bones (91.4\% in Layer 3F, 94.7\% in Layer 3B), documented as stages 1 and 2 of the Behrensmeyer (1978) system, indicate that the assemblages were buried within a relatively short time after the site was abandoned.

The high fragmentation of the bones is reflected in two features of the assemblages. First, roughly 13 percent of the specimens in the coordinated assemblages are smaller than $3 \mathrm{~cm}$ in length (teeth not included). Second, many limb bone shafts were significantly reduced in size. For example, 80 percent of the shafts from Layer $3 \mathrm{~B}$ had preserved less than 50 percent of their original circumference. Less than one quarter of 
Table i. Taxa Represented by the Bone Assemblage from Layer 3F and Layer 3B

\begin{tabular}{lrrrrr}
\hline & \multicolumn{2}{c}{ LAYER $3 \mathrm{~F}$} & & \multicolumn{2}{c}{ LAYER 3B } \\
\cline { 2 - 3 } \cline { 5 - 6 } TAXON OR SIZE $^{\mathrm{a}}$ & NISP & $\%$ & & NISP & $\%$ \\
\hline Equidae & 307 & 20.4 & & 499 & 35 \\
Bos primigenius & 375 & 24.9 & & 72 & 5 \\
Cervidae gen. et sp. indet. & 140 & 9.3 & & 16 & 1.1 \\
Gazella sp. & 17 & 1.1 & & 24 & 1.7 \\
Rhinocerotidae gen. et sp. indet. & 5 & 0.3 & & 1 & 0.07 \\
Camelus & 0 & 0 & & 1 & 0.07 \\
Sus scrofa & 5 & 0.3 & & 3 & 0.2 \\
Ochotona alpina & 0 & 0 & & 1 & 0.07 \\
Rodentia & 3 & 0.2 & & 2 & 0.14 \\
Carnivora & 1 & 0.07 & & 5 & 0.35 \\
Aves & 1 & 0.07 & & 1 & 0.07 \\
Extra-large mammal & 32 & 2.1 & & 4 & 0.28 \\
Large mammal & 346 & 22.9 & & 293 & 20.6 \\
Medium-sized mammal & 252 & 16.7 & & 424 & 29.7 \\
Small mammal & 23 & 1.5 & & 71 & 5 \\
Extra-small mammal & 1 & 0.07 & & 8 & 0.56 \\
& & & & 100 \\
Total & 1508 & 100 & 1425 & \\
\hline
\end{tabular}

NISP, number of identified specimens.

${ }^{\text {a }}$ Extra-large: rhino or mammals similar in size; large: mammals similar in size to Bos, Equus; medium: similar to medium-sized Cervidae; small: rabbit, small carnivores, or those similar in size.

the complete circumference was preserved in 47 percent of the long bones in Layer 3F and 38 percent of the long bones in Layer 3B. Furthermore, many shafts are characterized by V-shaped fracture lines (51\% of limb bones in Layer 3F, 48\% of limb bones in Layer 3B), indicating that these long bones had been broken or fractured when they were fresh. The impact fractures and surface modifications described in detail in the following section indicate that humans were the main agents responsible for destroying and discarding the bones.

The orientation and light degree of rounding of bone fragments, as well as the horizontal distribution of lithics and bones of different sizes, suggest that the Laonainaimiao assemblage was only lightly damaged or modified by sedimentary activity. This is supported by the geological setting of the site, which is in a low-energy environment.

Bone density is a key taphonomic factor that should be considered before we derive any conclusion about cultural behavior from a faunal assemblage. Studies have shown that bone destruction and loss can be correlated with bone density (Lam et al. 1998; Lyman 1984, 1994). When examining bone survivorship (\%MAU) in relation to bone density (values from Lyman 1994), we found no apparent correlation for Equidae (in Layer 3F, Spearman's $r=0.511, p=0.062$ ) and Bos (Bos primigenius in Layer 3F, Spearman's $r=0.446, p=0.110)$. It seems that non-human and mechanical factors were not significant for density attrition. This is also supported by the rarity of marks from carnivore gnawing and the few mechanical modifications. Besides the scarcity of 
comparatively high-density animal parts (e.g., phalanx, carpal, or tarsal), low-density portions (e.g., axial remains or epiphyses of long bones) are also rarely recovered. Our analysis of the bones at Laonainaimiao, outlined in the next section, suggests that they likely underwent attrition from the ways in which humans processed and utilized animal carcasses.

In sum, bones from Layer 3F and Layer 3B record a similar taphonomic history. They are in a good state of preservation. Human activities are mostly responsible for damaging and modifying the bones, indicating intensive bone processing and utilization, while the role of carnivores and sedimentary activity was very limited.

\section{FOOD TRANSPORT AND PROCESSING}

In order to examine the skeletal part representation of the Equidae and Bos primigenius, the number of identified specimens (NISP), the minimum number of skeletal elements $(\mathrm{MNE})$, and percentage of the minimum number of animal units (\%MAU) were estimated (Table 2 and Table 3). The skeletal parts of Equidae in Layer 3F are unevenly represented. Tibia, skull, and mandible are over-represented. The scarcity of epiphyses and the high degree of limb bone fragmentation make long bone identification difficult. The seeming over-representation of tibia may be related to analytical bias because of easier identification. The innominate, upper limbs, metapodials, and scapula are also relatively well represented. Axial remains and foot bones occur infrequently, however. When survivorship (\%MAU) of Equidae is compared to the utility index (Outram and Rowley-Conwy 1998), there is no correlation (Spearman's $r=0.06$, $p=0.833)$. This means that skeletal parts were not selectively transported according to food value. When considering the good representation of most skeletal parts of Equidae, it is likely that whole carcasses were brought to the site.

As for Bos primigenius, mandible, front limbs, and metatarsals are over-represented, scapulae and hind limbs are generally well-represented, but axial remains are absent and

Table 2. Abundance of Skeletal Elements and Portions of Equidae in Layer 3F

\begin{tabular}{lrrr}
\hline EQUIDAE & NISP & MNE & $\%$ MAU \\
\hline Skull & 12 & 6 & $66.7 \%$ \\
Mandible & 53 & 12 & $66.7 \%$ \\
Cervical vertebrae & 1 & 1 & $2.2 \%$ \\
Thoracic vertebrae & 2 & 2 & $1.1 \%$ \\
Lumbar vertebrae & 1 & 1 & $2.2 \%$ \\
Scapula & 10 & 5 & $27.8 \%$ \\
Innominate & 13 & 8 & $44.4 \%$ \\
Humerus & 19 & 9 & $50.0 \%$ \\
Ulna & 7 & 2 & $11.1 \%$ \\
Radius & 7 & 2 & $11.1 \%$ \\
Femur & 10 & 7 & $38.9 \%$ \\
Tibia & 25 & 18 & $100.0 \%$ \\
Metacarpal & 4 & 4 & $22.2 \%$ \\
Metatarsal & 9 & 7 & $38.9 \%$ \\
Phalanx & 2 & 2 & $2.2 \%$ \\
\hline
\end{tabular}


Table 3. Abundance of Skeletal Elements and Portions of Bos primigenius in Layer 3F

\begin{tabular}{lrrr}
\hline BOS PRIMIGENIUS & NISP & MNE & \%MAU \\
\hline Horn & 15 & 8 & $40 \%$ \\
Skull & 14 & 6 & $60 \%$ \\
Mandible & 56 & 20 & $100 \%$ \\
Cervical vertebrae & 0 & 0 & $0 \%$ \\
Thoracic vertebrae & 0 & 0 & $0 \%$ \\
Lumbar vertebrae & 0 & 0 & $0 \%$ \\
Scapula & 15 & 9 & $45 \%$ \\
Innominate & 1 & 1 & $5 \%$ \\
Humerus & 35 & 20 & $100 \%$ \\
Ulna & 28 & 14 & $60 \%$ \\
Radius & 30 & 16 & $80 \%$ \\
Femur & 11 & 9 & $45 \%$ \\
Tibia & 20 & 8 & $40 \%$ \\
Metacarpal & 15 & 7 & $35 \%$ \\
Metatarsal & 19 & 17 & $85 \%$ \\
Phalanx & 2 & 2 & $3 \%$ \\
\hline
\end{tabular}

there are very few foot bones. Bone survivorship (\%MAU) and the food utility index (according to Emerson 1990; see also Lyman 1994) show no apparent correlation (Spearman's $r=-0.136, p=0.63$ ). Thus, humans probably used a similar strategy in transporting aurochs as they did for Equidae, such that the majority of skeletal parts or nearly the whole carcass would have been brought to the site. Given their large size and heavy weight, it would have been very difficult to carry aurochs for a long distance; it is therefore likely that aurochs were hunted close to the site. One explanation for the rare recovery of axial and foot bones could be that these parts were abandoned after primary butchery outside the site and not selected for transport. However, axial parts of the body contain a large amount of meat, so there should be no reason to discard them. Meanwhile, no clear signs of primary butchery are indicated.

Both vertebrae and phalanges were rarely identified due to a high degree of fragmentation, possibly because of intensive processing for marrow and grease. As far as the phalanges are concerned, it is difficult to disarticulate metapodials and feet, and keeping the phalanges would facilitate carrying the carcass. Although the phalanges have a relatively high bone mineral density (Lyman 1994), it is thus very likely that the axial elements and feet were lost on site for food-related reasons. Overall, the skeletal representations from Laonainaimiao do not show a significant selective profile suggesting a focus on the highest yield parts or special valued parts. This suggests that people were compelled to utilize as much as they could of the entire carcass due to the scarcity of food on site or the closeness of killing places to the site (Binford 1978).

Human modifications to the bones were identified, offering clues to butchery and consumption practices at Laonainaimiao. Only 1.6 percent of the Equidae bones from the Layer 3F assemblage bear cut marks. Cut-marks were identified on pelves, mandibles, tibia shafts, and ulna shafts. Among all the identified specimens of Layer 3F, the proportion of bones showing scars (i.e., conchoidal flake scars, notches) from strong impact forces is 3.3 percent $(n=62)$. Such modifications are particularly present on the shafts and 
mandibles of large and medium-sized mammals. Anthropogenic modifications to the bones from Layer $3 \mathrm{~B}$ exhibit the same pattern: 2 percent have cut marks $(n=40)$ and 2.5 percent have impact marks $(n=48)$. Cut marks are seen on humerus, radius, rib, mandible, and axial bones and chop marks are seen on one mandible bone. Bones with impact scars include the shafts of upper front limbs, lower front limbs, and upper and lower parts of hind limbs, as well as the body of the mandibles. The anthropogenic marks indicate that butchery and processing was practiced on site.

The carcasses were intensively butchered and processed not only for the meat, but more importantly for marrow and grease. Wild horse was probably a preferred source of marrow. That horse bone marrow was consumed quite often is indicated by the following evidence: (1) most of the limb shafts and mandibles were considerably broken, with less than 25 percent of limb circumference preserved in 47 percent of Layer $3 \mathrm{~F}$ shafts and 38 percent of Layer 3B shafts; (2) signs of percussion marks frequently appear on or near the fractures of the limbs and mandibles, a type of fracture likely produced in the process of marrow-extraction (Bar-Oz 2004); and (3) 32 pieces of small bone flakes recovered among the piece-plotted assemblages seem to have been removed from the edges of bones by the application of a heavy impacting force.

To further test the marrow-extraction explanation, the degree of bone fragmentation is compared with the Marrow Index (Outram and Rowley-Conwy 1998). The result shows a positive relationship (Spearman's $r=0.746, p=0.054$ ). Taking the marrow content of Zebra limbs as an example (Blumenschine and Madrigal 1993), the wild horse tibia probably contained the most marrow, followed by the metatarsal, femur and humerus, and radius and metacarpal. Aside from identification bias, the dominance of tibia in the Equidae assemblage might therefore be the result of marrow extraction. This would also explain the good representation and high fragmentation of metatarsals and upper limbs. The breaking of skulls and mandibles was probably also done in order to obtain marrow. Because of the thickness of the cortical bone and the small medullary cavity, the amount of marrow in the limb shaft of a horse is lower than in other large ungulates, however (Levine 1998). This may have pushed people to focus on aurochs as well as horses, particularly when they greatly valued marrow for food, even though aurochs were more difficult and dangerous to capture.

Evidence of carnivore damage to the bones is rare; it is found on only 0.1 percent of the bones in both layers. Rodent damage is found on 0.2 percent of the bones in Layer 3B. This may result from long-term human habitation of the site, perhaps for weeks or months at a time, during which carnivores could not gain access to discarded remains. This is supported by Chen's (2015) argument that Layer 3F records multiple occupations over a relatively long period, in light of the high density of artifacts and the pattern of repeated building of fireplaces. Alternatively, lack of carnivore damage to the bone assemblage may be due to the thorough processing of faunal resources, which would have left few remains for carnivores to scavenge.

Since carnivore intervention can be ruled out and the assemblages were not much damaged by sedimentary activity, the scarcity of axials and epiphyses likely result from humans pounding these low-density bones into small, fragile pieces in order to collect the grease, which put these parts beyond the scale of identification. Grease-rich cancellous elements and vertebrae are highly valued for calories and nutrients by foragers. Limb shafts and ribs are also useful for grease extraction (Binford 1978). However, grease processing is difficult to detect in the archaeological record. Bones processed for grease are expected to be highly fragmented and to have a low 
survivorship (Munro and Bar-Oz 2005). Among the unidentified specimens and those classified to size group, 38 percent are smaller than $3 \mathrm{~cm}$. High fragmentation is also seen in pieces of mandibles, crania, ribs, and limbs. In the Equidae assemblage of Layer 3F, vertebrae, ulnas, radiuses, and phalanges have low survivorship, while vertebrae are missing and the innominate bones and phalanges have low survivorship in the Bos assemblage (Table 2 and Table 3). Carpals and tarsals, which contain little if any marrow but reasonable amounts of grease, are absent from both of the assemblages. It is possible that carpals and tarsals were broken for processing grease. If these skeletal parts did not survive well due to grease extraction, we would expect to find other clues that grease rendering was conducted, including heating rocks, stone anvils, and evidence of firing and stewing (Stiner 2005). At Laonainaimiao, several fireplaces were uncovered and large rocks were found close to some of them (Chen 2015). These finds strengthen the grease processing explanation. However, more evidence is needed to test the possibility that grease was processed at the site.

\section{HUNTING BEHAVIOR}

The representation of skeletal parts and butchery and processing marks all suggest that the foragers camping at Laonainaimiao had primary access to large ungulates such as wild horse or wild ass and aurochs. They succeeded in maximizing exploitation of these resources. The age of Equidae and Bos are estimated by tooth eruption and wear stages (Hillson 2005). Among the Equidae in Layer 3F, 69.2 percent (NISP = 18) are adults, 19.2 percent (NISP $=5$ ) are juveniles and sub-adults, and 11.5 percent $(\mathrm{NISP}=3)$ are old individuals. Bos bones demonstrate a similar adult-dominant profile, with 70 percent $(\mathrm{NISP}=14)$ adults, 15 percent $(\mathrm{NISP}=3)$ juveniles and sub-adults, and 15 percent $(\mathrm{NISP}=3$ ) old adults (percentages are calculated based on NISP). In Layer 3B, 71.1 percent (NISP $=32$ ) of the Equidae are adults, 22.2 percent $(\mathrm{NISP}=10)$ are juveniles, and 6.7 percent (NISP $=3$ ) are old. Preying on large mammals enhanced the possibility of getting more meat, marrow, and fat most importantly, which made a substantial contribution to the diet of foragers, especially during harsh and lean seasons (Speth 1983). However, hunting large ungulate species such as aurochs was a dangerous task and required an advanced degree of social cooperation (Hawkes et al. 2001; O'Connell et al. 2002). Apparently, knowledge of animal behavior and the ability to expend a large amount of energy characterized these groups of hunters. The constant acquisition oflarge game at Laonainaimiao reflects a high demand for large quantities of meat and fat and indicates close cooperative behavior in hunting.

\section{CONCLUSION}

The taphonomic history and archaeofauna study of Laonainaimiao offers insight into human subsistence strategy in terms of food acquisition, transport, and processing at around 40,000 B.P. The faunal taxa indicate the environmental dominance of a mosaic landscape of grassland and patchy forest. It is worth noting that more horses and a few more gazelles are represented in Layer 3B; the wild camel also appeared in this layer. This faunal association points to a drier steppe environment suitable for aurochs and ostrich. Despite this, the occurrence of aurochs and ostrich decreased in Layer 3B, while medium-sized and small mammals occurred more. We suggest that the changing frequencies of mammal remains from Layer 3F to Layer 3B may reflect changes in the 
range of hunting territory and subsistence strategy. Combined with the evidence of the lithic industry and fireplaces, it is likely that humans occupied the site for a shorter time and less intensively during the Layer 3B period than during the Layer 3F period, where they may have camped for longer periods of time (Chen 2015). In the time period associated with Layer 3B, humans might not have spent much effort or taken as many risks in hunting aurochs and acquiring ostrich eggs, both of which require luck and searching time. They focused instead on hunting horses as well as medium-sized and small animals, which could be acquired with comparatively less risk and energy costs.

A large number of faunal remains accumulated from such human activities, but that they escaped the destruction by carnivores after site abandonment is indicated by the low frequency of gnawing marks. The comparative abundance of anthropogenic modification marks suggests instead that carcasses were brought to the site for intensive processing. The good preservation of the bone assemblages might be attributed to long periods of human occupation at the site and the thorough utilization of the animal resources, which left nothing for carnivores to eat, as well as the rapid accumulation of floodplain deposits above the living floors.

The recovered bones present a dominance of adult Equidae (in Layer 3F and Layer 3B) and adult aurochs (in Layer 3F). Hunting adult individuals allowed these foragers to obtain more meat, marrow, and fat. Based on the analysis of skeletal part representation, bone survivorship, and bone modifications, nearly entire carcasses of these large ungulates were carried to the site for butchery and consumption. Game animals were defleshed and their bones were intensively broken for marrow and pounded into tiny pieces for grease. The intensive utilization of the carcasses reflects a very high food demand. Such a behavioral pattern may have resulted from the low availability of food in the palaeoenvironment, seasonality, or group size, or from poor quality of food, which pushed people to maximize the use of each carcass. This proposal remains open for discussion, however, and requires additional palaeoclimatic investigation and full-scale analysis of the site. Nevertheless, we conclude that the consistent search for large ungulates as demonstrated in the Laonainaimiao bone assemblages reflects depths of human planning and group cooperation in foodacquisition strategies during the late Middle Palaeolithic in the Chinese Central Plains.

\section{ACKNOWLEDGMENTS}

We would like to thank Rowan Flad and three anonymous reviewers for valuable comments to this manuscript. Thanks also goes to Mary Prendergast for useful discussions and suggestions about the research. Special thanks to all the members of the archaeological team at Laonainaimiao site. This research was supported by Social Science Foundation of China (14CKG015, 11\&ZD120).

\section{REFERENCES CITED}

BAR-Oz, GUY

2004 Epipaleolithic Subsistence Strategies in the Levant: A Zooarchaeological Perspective. Boston: Brill Academic Publishers, Inc.

Behrensmeyer, AnNa K.

1978 Taphonomic and ecologic information from bone weathering. Paleobiology 4:150-162. 
BINFORD, LOUIS

1978 Nunamuit Ethnoarchaeology. New York: Academic Press.

Blumenschine, Robert J., and T. Cregg Madrigal

1993 Variability in long bone marrow yields of East African ungulates and its zooarchaeological implications. Journal of Archaeological Science 20(5):555-587.

Bö̈da, E., Y. M. Hou, H. Forestier, J. Sarel, and H. M. Wang

2013 Levallois and non-Levallois blade production at Shuidonggou in Ningxia, North China. Quaternary International 295:191-203.

CHEN Youcheng 陈宥成

2015 Songshan donglu MIS3 jieduan renqun shiqijishu yu xingweimoshi-Laonainaimiao yizhi yanjiu. 嵪山东麓 MIS3 阶段人群石器技术与行为模式一老奶奶庙遗址研究 [Lithic technology and human behavior of the foragers during the MIS3 along the eastern foot of Songshan Mountain: The study of Laonainaimiao site]. Ph.D. diss. Peking University.

Chen Youcheng 陈宥成 AND Qu Tongli 曲彤丽

2016 Panzhuang shihe xiangguan wenti tantao. 盘状石核相关问题探讨 [Discussions on discoid core in China]. Kaogu 考古 2:88-94.

EMERson, A. M.

1990 Archaeological implications of variability in the economic anatomy of Bison bison. Ph.D. diss. Washington State University.

Gao Xing and Christopher J. Norton

2002 A critique of the Chinese 'Middle Palaeolithic.' Antiquity 76:397-412.

Hawkes, K., J. F. O’Connell, and N. G. Blurton Jones

2001 Hunting and nuclear families: Some lessons from the Hadza about men's work. Current Anthropology 42:681-709.

Hillson, S.

2005 Teeth, $2^{\text {nd }}$ ed. Cambridge: Cambridge University Press.

Lam, Y. M., Xingbin Chen, Curtis W. Marean, and Carol J. Frey

1998 Bone density and long bone representation in archaeological faunas: Comparing results from CT and photon densitometry. Journal of Archaeological Science 25(6):559-570.

LeVIne, M. A.

1998 Eating horses: The evolutionary significance of hippophagy. Antiquity 72(275):90-100.

Li FENG

2014 Fact or fiction: The Middle Paleolithic in China. Antiquity 88:1303-1309.

Li, F., S. Kuhn, F. Y. Chen, Y. H. Wang, J. Southon, F. Peng, M. C. Shan, C. X. Wang, J. Y. Ge

X. M. Wang, Y. Tala, and X. Gao

2018 The easternmost Middle Paleolithic (Mousterian) from Jinsitai Cave, North China. Journal of Human Evolution 114:76-84.

LiN SHENGLONG 林圣龙

1996 Zhongxifang jiushiqi wenhuazhong de jishu moshi de bijiao 中西方旧石器文化中的技术模 式的比较 [Comparison of technological mode of Palaeolithic culture between China and the West]. Acta Anthropologica Sinica 人类学学报 15:1-20.

LyMAN, LeE R.

1984 Bone density and differential survivorship of fossil classes. Journal of Anthropological Archaeology 3:259-299.

1994 Vertebrate Taphonomy. Cambridge: Cambridge University Press.

Munro, Natalie D., and Guy Bar-Oz

2005 Gazelle bone fat processing in the Levantine Epipalaeolithic. Journal of Archaeological Science 32(2):223-239.

Nian, Xiaomei, Xing Gao, and Liping Zhou

2014 Chronological studies of Shuidonggou (SDG) Locality 1 and their significance for archaeology. Quaternary International 347:5-11.

NingXIa WenWU KaOgU YanjIU SUO 宁夏文物考古研究所

2003 Shuidonggou: 1980 nian fajue baogao 水洞沟: 1980 年发掘报告 [Shuidonggou: The Excavation Report 1980]. Beijing: Kexue Chubanshe. 
Norton, Christopher J., and Xing Gao

2008 Hominin-carnivore interactions during the Chinese Early Paleolithic: Taphonomic perspectives from Xujiayao. Journal of Human Evolution 55(1):164-178.

O’Connell, J. F., K. Hawkes, K. D. Lupo, and N. G. Blurton Jones

2002 Male strategies and Plio-Pleistocene archaeology. Journal of Human Evolution 43(6):831-872.

Outram, Alan, and Peter Rowley-Conwy

1998 Meat and marrow utility indices for horse (Equus). Journal of Archaeological Science 25(9):839-849.

SPETH, John D.

1983 Energy source, protein metabolism, and hunter-gatherer subsistence strategies. Journal of Anthropological Archaeology 2(1):1-31.

STINer, Mary C.

2005 The Faunas of Hayonim Cave, Israel: A 200,000-year Record of Paleolithic Diet, Demography, and Society. Cambridge: Harvard University.

YeE, MeI KeI

2012 The Middle Paleolithic in China: A review of current interpretations. Antiquity 86:619-626.

Yu JiANJUN 于建军 AND HE JiANING 何嘉宁

2017 Xin Jiang Jimunai Tongtian Dong Yizhi Fajue Zhongyao Shouhuo [The Discovery of Tongtian cave (Jimunai County, Xinjiang)]. Zhongguo Wenwubao 中国文物报 第八版 (newsletter dated 1 December).

ZHANG SHUANGQUAN 张双权, GAO XING 高星, ZHANG YUE 张乐, AND Li ZHANYANG 李占扬

2011 Lingjing dongwuqun de maicangxue fenxi ji zhongguo beifang jiushiqishidai zhongqi shoulietuzai yizhi de shouci jilu 灵井动物群的埋藏学分析及中国北方旧石器时代中期的狩猎屠宰遗址的首次记录 [Taphonomic analysis of the Lingjing fauna and the first report of a Middle Paleolithic kill-butchery site in North China]. Kexue Tongbao 科学通报 56(35):2988-2995.

ZHANG Yue 张乐, WANG CHUNXue 王春雪, ZHANG SHUANGQUAN 张双权, AND GAO XING 高星

2009 Ma'anshan jiushiqishidai yizhi gurenlei xingwei de dongwukaoguxue yanjiu 马鞍山旧石器时 代遗址古人类行为的动物考古学研究 [A zooarchaeological study of bone assemblages from the Ma'anshan paleolithic site]. Science China Series D-Earth Science 中国科学 (D辑: 地球科学) 39(9):1256-1265.

ZHAO, S.

1994 Geography of China: Environment, Resources, Population and Development. New York: John Wiley and Sons.

ZhengZhou Shi Wenwu Kaogu Yanjiu Suo 郑州市文物考古研究所, Beijing Daxue KaOgu Wenbo XUEYUAN 北京大学考古文博学院, AND ZHENGZHOU SHI ERQI QU WENHUA LuYOU Ju 郑州市二七区 文化旅游局

2012 Zhengzhou Laonainaimiao Yizhi Ji Songshan Dongnanlu Jiushiqi Didianqun. 郑州老奶奶庙 遗址暨嵩山东南麓旧石器地点群 [The discovery of Laonainaimiao site in Zhengzhou and the site clusters at the southeastern foothill of Mtn. Song]. Zhongguo Wenwubao 中国文物报 第四版 (newsletter dated 13 January). 